\begin{tabular}{|c|c|c|}
\hline Case Reports in & \multicolumn{2}{|c|}{ Case Rep Gastroenterol 2015;9:106-112 } \\
\hline Gastroenterology & $\begin{array}{l}\text { DOI: 10.1159/000381637 } \\
\text { Publisned online: April Z4, } 2015\end{array}$ & $\begin{array}{l}\text { (c) } 2015 \text { S. Karger AG, Basel } \\
1662-0631 / 15 / 0091-0106 \$ 39.50 / 0 \\
\text { www.karger.com/crg }\end{array}$ \\
\hline & \multicolumn{2}{|c|}{$\begin{array}{l}\text { This is an Open Access article licensed under the terms of the Creative Commons } \\
\text { Attribution-NonCommercial } 3.0 \text { Unported license (CC BY-NC) (www.karger.com/OA } \\
\text { license), applicable to the online version of the article only. Distribution permitted for non } \\
\text { commercial purposes only. }\end{array}$} \\
\hline
\end{tabular}

\title{
New Onset, Aggravation and Recurrence of Crohn's Disease upon Treatment with Three Different Tumor Necrosis Factor Inhibitors
}

\author{
Jonas Zeitz $^{\mathrm{a}}$ Susann Enderlin ${ }^{\mathrm{b}}$ Luc Biedermann $^{\mathrm{a}}$ \\ Matthias Turina $^{c}$ Sebastian Leibl ${ }^{d}$ Meher Prakash $^{a}$ \\ Gerhard Rogler $^{a}$ Benjamin Misselwitz ${ }^{a}$ \\ ${ }^{a}$ Division of Gastroenterology and Hepatology, ${ }^{b}$ Division of Rheumatology, \\ ${ }^{\mathrm{C}}$ Department of Visceral and Transplant Surgery and ${ }^{\mathrm{d}}$ Division of Pathology, \\ University Hospital Zurich, University of Zurich, Zurich, Switzerland
}

\section{Key Words}

Inflammatory bowel disease · Crohn's disease - Tumor necrosis factor inhibition .

Autoimmune-like syndromes

\begin{abstract}
Tumor necrosis factor (TNF) is a major cytokine in the pathogenesis of inflammatory bowel disease (IBD), and TNF inhibition is a cornerstone of contemporary IBD therapy. However, paradoxical induction of IBD has recently been reported upon treatment of rheumatologic disorders with TNF inhibitors. In previous cases, induction of IBD was associated with one single drug and IBD was successfully managed by switching TNF inhibitors. We report the case of a patient with juvenile rheumatoid arthritis under long-term treatment with etanercept. After switching TNF inhibition to adalimumab, symptoms of Crohn's disease (CD) occurred and the diagnosis of $C D$ was established by endoscopy. Further treatment with adalimumab and subsequently infliximab aggravated the abdominal symptoms, necessitating ileocecal resection, after which symptoms resolved for several months. Etanercept treatment due to recurrent rheumatologic symptoms was followed by recurrent CD symptoms and findings, which resolved upon discontinuation of etanercept. This case suggests that induction, aggravation and recurrence of IBD can be rare class effects of TNF inhibition.
\end{abstract}

(c) 2015 S. Karger AG, Basel

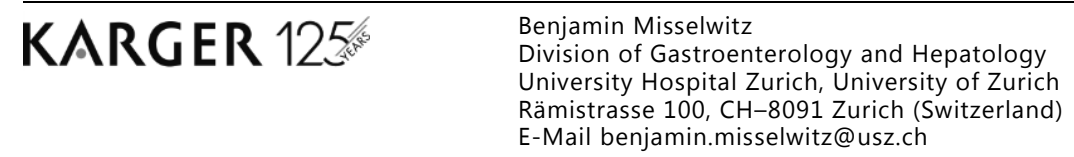


Zeitz et al.: New Onset, Aggravation and Recurrence of Crohn's Disease upon Treatment with Three Different Tumor Necrosis Factor Inhibitors

\section{Introduction}

Tumor necrosis factor (TNF) plays a central role in the pathogenesis of inflammatory bowel disease (IBD), and the introduction of TNF inhibitors has substantially broadened the therapeutic options in IBD [1]. Available monoclonal antibodies which are effective for the treatment of Crohn's disease (CD) and ulcerative colitis include infliximab and adalimumab [2]. In contrast etanercept, a fusion protein of the human soluble TNF receptor p75 with the Fc fragment of human immunoglobulin G1, was shown to be safe but not effective in CD [3]. The reasons for this differential effect of infliximab/adalimumab and etanercept are not understood, but might include complement-dependent cytotoxicity and induction of apoptosis by infliximab/adalimumab, but not by etanercept. Vice versa, lymphotoxin is bound and neutralized by etanercept, but not the antibodies [4].

Therapy with TNF inhibitors has an acceptable safety profile and besides infusion reactions, the adverse events of TNF inhibitor treatment are mainly infectious complications, including tuberculosis, as might be expected from their mode of action [5]. Paradoxical immune activation by TNF inhibitors has also been described, and autoimmune disorders, including psoriasis, vasculitis, systemic lupus erythematosus, interstitial lung disease and sarcoidosis, have been reported as adverse events of TNF inhibitor treatment [6]. The mechanisms of autoimmune-like syndromes during TNF blockade have not be clarified, but autoimmune-like syndromes might be caused by cytotoxicity of the drugs, increase of interferon- $\alpha$ levels by TNF, dysregulation of T cells and unrecognized infectious complications. Furthermore, direct or indirect effects of TNF inhibitors might induce exposure towards autoantigens, including self-DNA or self-RNA, which could act as endogenous ligands of Tolllike receptors and lead to autoimmunity [7].

Paradoxical induction of IBD by the TNF inhibitor etanercept has been described in seminal case reports and systematic analyses $[8,9]$. IBD as an adverse event of treatment is not limited to etanercept treatment, since recent case series also included cases of IBD induced by infliximab or adalimumab [10]. However, in the cases described, new-onset IBD could be treated by switching TNF inhibitors, usually to infliximab or adalimumab, and idiosyncratic effects of the culprit drugs could not be excluded. We report a case with new onset, progression and recurrence of CD upon treatment with three different TNF inhibitors, suggesting paradoxical induction of IBD as a class effect of TNF inhibitors.

\section{Case Presentation}

A 19-year-old man presented to our division for the management of severe right lower quadrant pain. His previous history was remarkable for juvenile rheumatoid arthritis starting at 12 years of age, involving the sacroiliac and mandibular joint as well as the right ankle and hip. He was tested positive for HLA-B27, but tests for antinuclear antibodies and rheumatoid factor proved to be negative. At 16 years of age etanercept $50 \mathrm{mg}$ s.c. was started which initially relieved the symptoms, so the dose was reduced to every 2 weeks after 1 year of treatment. However, 1 year later the joint pain recurred and was refractory to etanercept dose escalation (weekly) and add-on naproxen. Two months before the onset of abdominal pain the treatment regime was changed to adalimumab $40 \mathrm{mg}$ s.c. every 2 weeks and the patient remained free of rheumatologic problems for the next year.

During evaluation for abdominal pain, lower right quadrant tenderness and a palpable tumor were noted. Blood work revealed systemic inflammation (C-reactive protein $46 \mathrm{mg} / \mathrm{l}$ and leukocytosis with $13.7 \times 10^{9}$ leucocytes per liter with $84 \%$ neutrophils). Ultrasound and 
Zeitz et al.: New Onset, Aggravation and Recurrence of Crohn's Disease upon Treatment with Three Different Tumor Necrosis Factor Inhibitors

computed tomography suggested terminal ileitis and abdominal lymphadenopathy. Stool tests for microorganisms including Clostridium difficile were negative. Colonoscopy demonstrated an ulcerated ileocecal valve with a narrow opening that could not be intubated. Histology confirmed granulomatous inflammation and acute inflammation, and all tests for infectious diseases, including acid-fast staining, mycobacteria cultures and immunohistochemistry for cytomegalovirus, were negative.

Since the patient's presentation was consistent with new-onset CD, we continued adalimumab treatment and started budesonide at $9 \mathrm{mg} /$ day. Subsequently, abdominal pain improved; however, surveillance of small bowel inflammation by abdominal ultrasound continued to show wall thickening $>6 \mathrm{~mm}$, consistent with active inflammation, and budesonide was increased to $15 \mathrm{mg} /$ day. Due to recurrent abdominal symptoms treatment was switched to infliximab $5 \mathrm{mg} / \mathrm{kg}$ body weight, but abdominal pain only temporarily improved and recurred only 3 months after starting infliximab. The patient was now complaining of constant abdominal pain and had lost $12 \mathrm{~kg}$ of body weight (body mass index $16 \mathrm{~kg} / \mathrm{m}^{2}$ ). Magnetic resonance imaging revealed chronic terminal ileitis and a complex fistula system. In hospital parenteral nutrition was started, infliximab was stopped, and 9 months after the onset of abdominal pain, right-sided colectomy with an ileocolic anastomosis was performed (fig. 1). The immediate postoperative course was unremarkable; the patient remained free of symptoms and body weight increased.

Three months after surgery, joint inflammation recurred in the hips, shoulders, right foot, lumbar spine and sacroiliac joint. Due to limited therapeutic options for the treatment of ileosacral arthritis, etanercept $50 \mathrm{mg}$ s.c. weekly was restarted after careful discussion with the patient. Etanercept immediately relived joint pains, but 14 days after restarting the TNF inhibitor abdominal pain recurred, accompanied by an increase in calprotectin levels. Colonoscopy revealed multiple ulcers at the ileocolic anastomosis and histology confirmed ulceration. Abdominal pain slowly resolved after etanercept had been discontinued. The clinical course is summarized in figure 2.

\section{Discussion and Conclusions}

In our patient induction, aggravation and recurrence of CD occurred during treatment with three different TNF inhibitors (adalimumab, infliximab and etanercept). According to the Naranjo algorithm [11], a consensus algorithm to estimate the probability of causality in a suspected drug-induced clinical event, a definite association between TNF inhibitor treatment and CD as an adverse drug event is present in our patient (10 out of 13 possible points). Importantly, there has been no alternative explanation of IBD in our patient with a negative family history for IBD and only a brief period of naproxen treatment, which had been discontinued weeks before the initial onset of abdominal pain. However, some limitations of the Naranjo algorithm exist and some ambiguity remains: Following a recent analysis of new-onset IBD as an adverse event of TNF inhibitor treatment, we did not score juvenile idiopathic arthritis as an alternative explanation for IBD in our patient [12]. The possibility of joint involvement as an extraintestinal manifestation of IBD preceding the onset of CD for several years seems unlikely but cannot be rigorously excluded. For consistency, the Naranjo score was applied as in the previous larger study [12].

Proof for an association of IBD with TNF treatment is strongest for etanercept. In addition to seminal case reports, larger case series have now been published. Thereby, in a report from a European etanercept registry for treatment of juvenile idiopathic arthritis, 13 cases of new-onset IBD (including 9 cases with CD) were noted. The authors calculated a 
Zeitz et al.: New Onset, Aggravation and Recurrence of Crohn's Disease upon Treatment with Three Different Tumor Necrosis Factor Inhibitors

43-fold increased risk for IBD compared to the control population. Of note, 10 of the patients were subsequently treated with another TNF inhibitor ( 5 each, infliximab and adalimumab) [13]. A second case series from France identified 8 patients with juvenile idiopathic arthritis and etanercept treatment ( 5 cases with $\mathrm{CD}$ and 3 cases with unclassified colitis). The clinical course of all patients was favorable upon discontinuation of etanercept; 6 of 8 patients were successfully treated with infliximab [9].

Within the last years, infliximab and adalimumab have increasingly been used for the treatment of rheumatic disorders and, likely due to increased patient exposure, evidence of paradoxical induction of IBD was also observed for these antibodies. A recent French series described 16 patients with rheumatoid arthritis and new-onset IBD under TNF inhibitor treatment (14 cases with etanercept, 2 with adalimumab). Similarly to the previous series, most of the patients had CD ( 8 and 6 cases with CD and Crohn's-like disease, respectively, and 1 case with unclassified colitis), and all patients could be successfully treated by switching the TNF inhibitor to infliximab or adalimumab [10]. Finally, a recent publication analyzing all adverse events regarding TNF inhibitors reported to the FDA described 158 cases of new-onset IBD. Most of the cases involved etanercept, but 28 cases of infliximab, 24 cases of adalimumab and 1 case of golimumab were listed. 111 of the associations were regarded as 'possible' and 47 as 'probable' according to the Naranjo algorithm [12].

Taken together, the various case reports and case series reporting new-onset IBD upon etanercept treatment strongly suggest that etanercept can rarely trigger IBD in susceptible patients. Paradoxical induction of IBD by infliximab and adalimumab is also likely, even though the evidence is weaker. Therefore, TNF inhibition seems to have paradoxical proinflammatory properties which are usually extinguished by its anti-inflammatory effects. It is tempting to speculate that etanercept, which has no proven therapeutic effects against CD, can cause overt mucosal inflammation more often than infliximab or adalimumab, which are highly effective against IBD. Following this model, only in those few patients for whom the inflammatory process is completely resistant to TNF inhibition can inflammation progress to clinically overt CD.

Specific risk factors for the development of paradoxical IBD in patients exposed to etanercept or infliximab/adalimumab remain to be elucidated. In addition, it is unknown why TNF inhibition would trigger mainly CD or unclassified colitis. In any case, our report adds evidence regarding the great variability in the pathways utilized for the inflammatory process in different patients and suggests that TNF can be protective in at least a few patients [14].

The management of IBD cases triggered by TNF inhibitors is largely identical to that of classical IBD cases, and in addition to discontinuation of the offending drug, standard IBD treatment should be applied [15]. When appropriate, switching the TNF inhibitor also seems to be safe; however, if symptoms persist or worsen even upon treatment with a second inhibitor (as in our patient), alternative treatment options should be pursued.

In summary, we present the first case of a patient in whom the onset, aggravation and recurrence of CD were triggered by TNF inhibition with three different TNF inhibitors, and our results point to $\mathrm{CD}$ as a rare adverse event and a class effect of TNF inhibitors. 
Zeitz et al.: New Onset, Aggravation and Recurrence of Crohn's Disease upon Treatment with Three Different Tumor Necrosis Factor Inhibitors

\section{Author Contributions}

B. Misselwitz and J. Zeitz drafted the manuscript. G. Rogler, S. Enderlin, L. Biedermann, M. Turina, S. Leibl and M. Prakash edited the manuscript for important intellectual content. M. Prakash, B. Misselwitz, M. Turina and S. Leibl prepared the figures. All authors read and approved the final version of the manuscript.

\section{Disclosure Statement}

B. Misselwitz has received travel grants from Vifor and Novartis and speaker's honoraria from MSD and Tillots. L. Biedermann has received research support from UCB, travel grants from MSD, Abbvie and Vifor, and fees for consulting/advisory boards from MSD, Abbvie and UCB. G. Rogler has consulted to Abbott, Abbvie, Boehringer, Calypso, FALK, Genentech, Essex/MSD, Novartis, Pfizer, Roche, UCB, Takeda (Switzerland), Tillots and Vifor, has received speaker's honoraria from Astra Zeneca, Abbott, Abbvie, FALK, MSD, Phadia, Tillots, UCB, and Vifor, and has received educational grants and research grants from Abbot, Abbvie, Ardeypharm, Essex/MSD, FALK, Flamentera, Novartis, Roche, Tillots, UCB and Zeller. J. Zeitz has received a research grant from Abbvie. S. Leibl, S. Enderlin, M. Turina and M. Prakash have no conflict of interests.

\section{References}

1 Sandborn WJ, Targan SR: Biologic therapy of inflammatory bowel disease. Gastroenterology 2002;122: 1592-1608.

$>2$ Ford AC, Sandborn WJ, Khan KJ, Hanauer SB, Talley NJ, Moayyedi P: Efficacy of biological therapies in inflammatory bowel disease: systematic review and meta-analysis. Am J Gastroenterol 2011;106:644-659; quiz 660.

$>3$ Sandborn WJ, Hanauer SB, Katz S, Safdi M, Wolf DG, Baerg RD, Tremaine WJ, Johnson T, Diehl NN, Zinsmeister AR: Etanercept for active Crohn's disease: a randomized, double-blind, placebo-controlled trial. Gastroenterology 2001;121:1088-1094.

$\checkmark 4$ Marotte H, Cimaz R: Etanercept - TNF receptor and IgG1 Fc fusion protein: is it different from other TNF blockers? Expert Opin Biol Ther 2014;14:569-572.

$>5$ Targownik LE, Bernstein CN: Infectious and malignant complications of TNF inhibitor therapy in IBD. Am J Gastroenterol 2013;108:1835-1842; quiz 1843.

$\checkmark 6$ Perez-Alvarez R, Perez-de-Lis M, Ramos-Casals M, BIOGEAS study group: Biologics-induced autoimmune diseases. Curr Opin Rheumatol 2013;25:56-64.

7 Prinz JC: Autoimmune-like syndromes during TNF blockade: does infection have a role? Nat Rev Rheumatol 2011;7:429-434.

$>8$ Wiegering V, Morbach H, Dick A, Girschick HJ: Crohn's disease during etanercept therapy in juvenile idiopathic arthritis: a case report and review of the literature. Rheumatol Int 2010;30:801-804.

$\checkmark 9$ Dallocchio A, Canioni D, Ruemmele F, Duquesne A, Scoazec JY, Bouvier R, Paraf F, Languepin J, Wouters CH, Guillot M, Quartier P, Bader-Meunier B; SOFREMIP: Occurrence of inflammatory bowel disease during treatment of juvenile idiopathic arthritis with etanercept: a French retrospective study. Rheumatology (Oxford) 2010;49:1694-1698.

10 Toussirot E, Houvenagel E, Goëb V, Fouache D, Martin A, Le Dantec P, Dernis E, Wendling D, Ansemant T, Berthelot JM, Bader-Meunier B, Kantelip B; Le CRI: Development of inflammatory bowel disease during anti-TNF- $\alpha$ therapy for inflammatory rheumatic disease: a nationwide series. Joint Bone Spine 2012;79: 457-463.

11 Naranjo CA, Busto U, Sellers EM, Sandor P, Ruiz I, Roberts EA, Janecek E, Domecq C, Greenblatt DJ: A method for estimating the probability of adverse drug reactions. Clin Pharmacol Ther 1981;30:239-245.

12 Krishnan A, Stobaugh DJ, Deepak P: Assessing the likelihood of new-onset inflammatory bowel disease following tumor necrosis factor-alpha inhibitor therapy for rheumatoid arthritis and juvenile rheumatoid arthritis. Rheumatol Int 2015;35:661-668. 
Zeitz et al.: New Onset, Aggravation and Recurrence of Crohn's Disease upon Treatment with Three Different Tumor Necrosis Factor Inhibitors

13 Van Dijken TD, Vastert SJ, Gerloni VM, Pontikaki I, Linnemann K, Girschick H, Armbrust W, Minden K, Prince FH, Kokke FT, Nieuwenhuis EE, Horneff G, Wulffraat NM: Development of inflammatory bowel disease in patients with juvenile idiopathic arthritis treated with etanercept. J Rheumatol 2011;38:1441-1446.

$\$ 14$ Slebioda TJ, Kmiec Z: Tumour necrosis factor superfamily members in the pathogenesis of inflammatory bowel disease. Mediators Inflamm 2014;2014:325129.

15 Dignass A, Van Assche G, Lindsay JO, Lémann M, Söderholm J, Colombel JF, Danese S, D’Hoore A, Gassull M, Gomollón F, Hommes DW, Michetti P, O'Morain C, Oresland T, Windsor A, Stange EF, Travis SP; European Crohn's and Colitis Organisation (ECCO): The second European evidence-based consensus on the diagnosis and management of Crohn's disease: current management. J Crohns Colitis 2010;4:28-62.
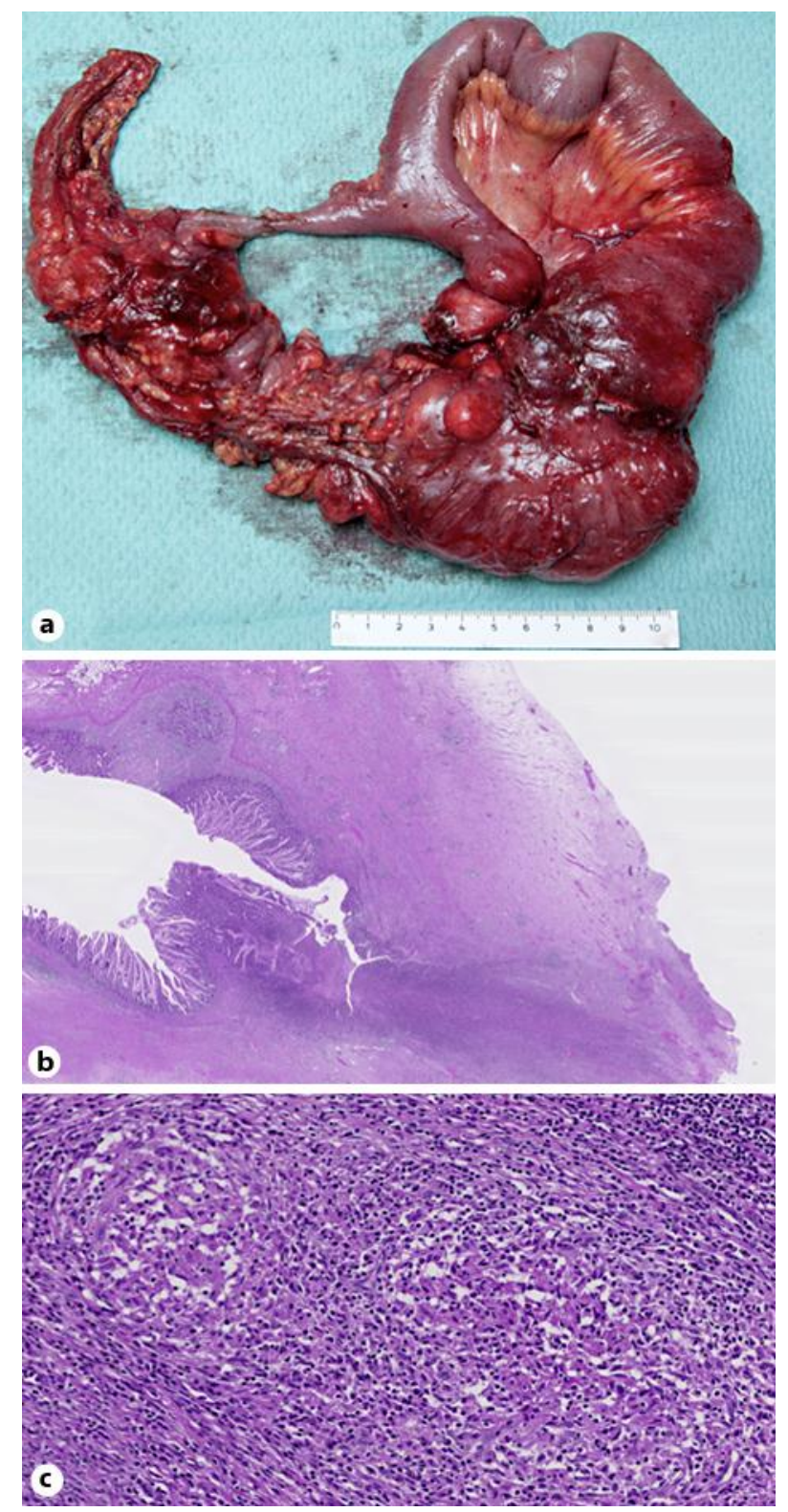

Fig. 1. Surgical specimen. a Macroscopic view. b Hematoxylin and eosin staining at 5-fold magnification revealing a fissure, transmural inflammation and architectural changes of the surrounding mucosa. c Hematoxylin and eosin staining at 100 -fold magnification revealing non-caseating granulomas within a draining lymph node. 


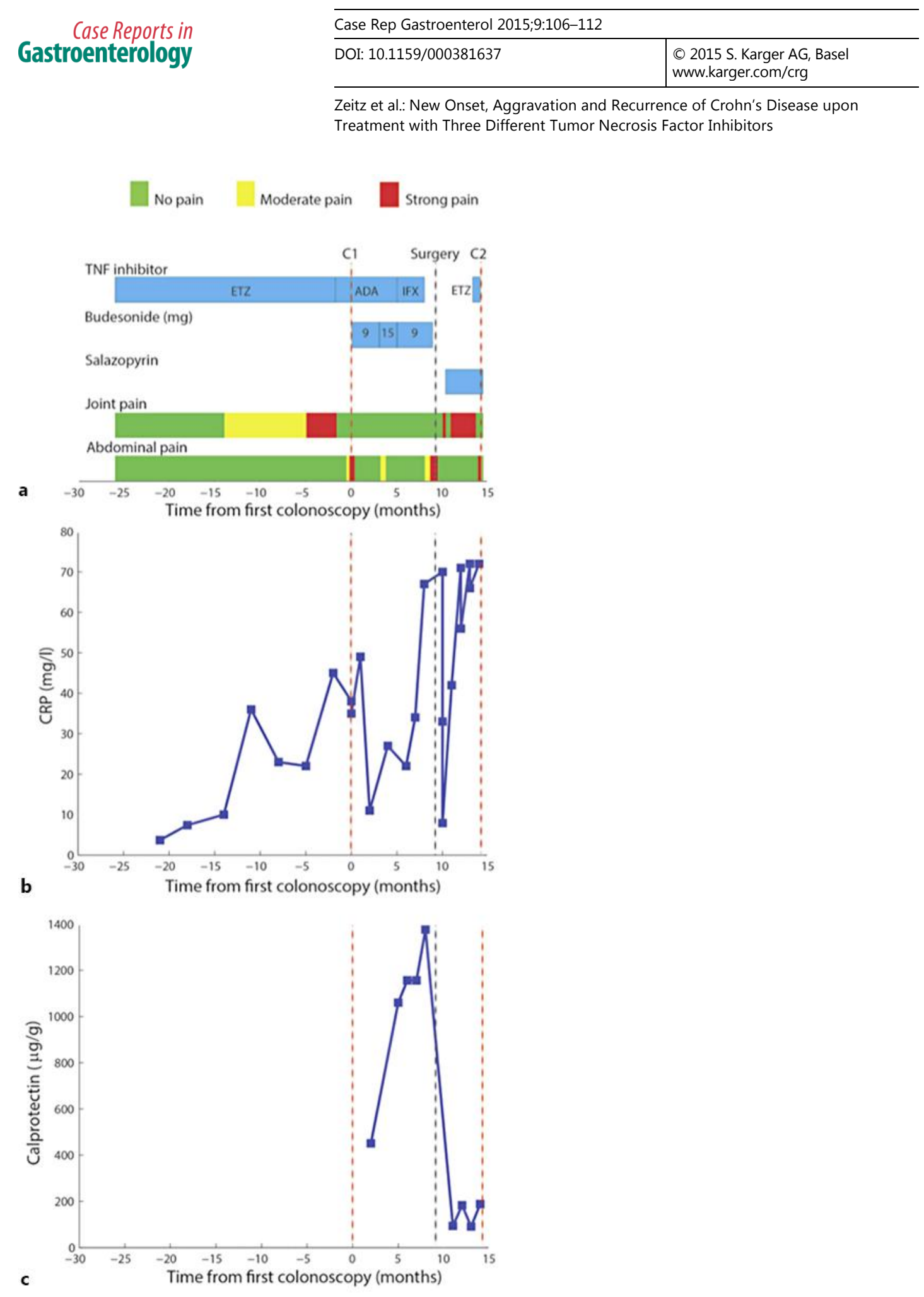

Fig. 2. a Overview of the clinical course. The time course of various pharmacological treatments and clinical symptoms is indicated. The time points of the first (C1) and second (C2) colonoscopy and the time point of surgery are marked. b Serum levels of C-reactive protein (CRP). $\mathbf{c}$ Levels of stool calprotectin. 